ISSN 1808-3765

\title{
TEORES DE MACRONUTRIENTES EM PLANTAS DE PIMENTÃO ENXERTADAS SOB FERTIRRIGAÇÃO
}

\section{EWERTON GASPARETTO DA SILVA ${ }^{\mathbf{1}}$; WILLIAM HIROSHI SUEKANE TAKATA ${ }^{1}$; MANOEL XAVIER DE OLIVEIRA JÚNIOR ${ }^{2}$; JÉSSICA DANILA DA SILVA $^{1}$ e RUMY GOTO ${ }^{1}$}

${ }^{1}$ FCA/UNESP. Rua Jose Barbosa de Barros, 1780, CEP 18610-307, Botucatu, SP. Fone: (14) 3811-7203. Email(s): wertogasparetto@hotmail.com; will.takata@gmail.com; duarte.jessicasilva@gmail.com ; rumy@fca.unesp.br

${ }^{2}$ IFMT -Campus Confresa. Av. Vilmar Fernandes 300, setor Santa Luzia, CEP: 78562-000, Confresa, MT. Fone (66) 3564-2600. manoelxjr@yahoo.com.br

\section{RESUMO}

Este estudo teve o objetivo de determinar os teores de macronutrientes (N, P, K, Ca, Mg e S) em plantas enxertadas pelos métodos contato bisel, garfagem por fenda cheia e encostia, comparadas as plantas não enxertadas (pé-franco), nos diferentes órgãos da planta, sob fertirrigação em ambiente protegido. O híbrido e o porta-enxerto utilizados foram o AF 7125 e AF 8253 respectivamente. Os nutrientes foram fornecidos via fertirrigação durante o ciclo de 150 dias. O experimento foi desenvolvido na Fazenda de Ensino, Pesquisa e Produção São Manuel, no município de São Manuel - SP pertencente FCA-UNESP, Campus de Botucatu $\mathrm{SP}$, e constou de quatro tratamentos e cinco repetições. Cada parcela foi composta por 12 plantas. Realizaram-se as análises químicas em uma planta por parcela aos 35, 85, 112 e 143 dias após transplante, para determinar a concentração dos nutrientes. Os resultados mostram que a concentração de macronutrientes na ordem decrescente na parte vegetativa (folha + caule) foi: $\mathrm{K}>\mathrm{N}>\mathrm{Ca}>\mathrm{Mg}>\mathrm{S}>\mathrm{P}$; já nos frutos foi: $\mathrm{K}>\mathrm{N}>\mathrm{P}>\mathrm{S}>\mathrm{Mg}>\mathrm{Ca}$. A concentração dos macronutrientes foi equivalente entre as plantas enxertadas quando comparando com pé-franco e que o porta-enxerto pode influenciar na absorção e translocação de minerais nas plantas enxertadas.

Palavras-Chave: Concentração de nutrientes, ambiente protegido gotejamento, Capsicum annuum L.

\section{SILVA, E. G; TAKATA, W. H. S.; OLIVEIRA JUNIOR, M. X.; SILVA, J. D; GOTO, R. MACRONUTRIENT LEVELS IN GRAFTED PEPPER PLANTS UNDER FERTIGATION}

\section{ABSTRACT}

This study aimed at determining the levels of macronutrients $(\mathrm{N}, \mathrm{P}, \mathrm{K}, \mathrm{Ca}, \mathrm{Mg}$ and $\mathrm{S})$ in grafted plants by contact methods such as bevel, cleft grafting by full rift and approach, as compared to non grafted plants. Analyses were performed in different parts of the plants under fertigation in a greenhouse. The hybrid and rootstock were AF 7125 and AF 8253, respectively. The nutrients were supplied via fertigation during the 150-day cycle. The 
experiment was carried out at the Teaching, Research and Production Farm in São Manuel city, SP which belongs to FCA-UNESP Campus in Botucatu city/SP. A total of 4 treatments and 5 replications were used. Each plot consisted of 12 plants. Chemical analyses were performed in one plant per plot at 35, 85, 112 and 143 days after transplantation to determine nutrient concentrations. The results showed that the macronutrient concentrations in a decreasing sequence in the vegetative parts (leaf + stem) were as follows: $\mathrm{K}>\mathrm{N}>\mathrm{Ca}>\mathrm{Mg}>$ $\mathrm{S}>\mathrm{P}$; and in the fruits: $\mathrm{K}>\mathrm{N}>\mathrm{P}>\mathrm{S}>\mathrm{Mg}>\mathrm{Ca}$. Macronutrient concentrations were similar among grafted plants as compared to ungrafted plants, and the rootstock may have influenced absorption and translocation of minerals in grafted plants.

Keywords: nutrient concentration, drip, protected environment, Capsicum annuum L.

\section{INTRODUÇÃO}

O pimenteiro (Capsicum annum L.) destaca-se, entre as solanáceas, por ser consumido em grande quantidade, além de possuir grande importância econômica no Brasil e entre as dez hortaliças de maior importância econômica nos país, com uma produção de 50.338 mil toneladas no ano de 2010 (Agrianual, 2012).

Com o crescente aumento da população mundial, tem-se a necessidade de se produzir mais, para atender a diferença gerada entre oferta e o consumo de alimentos. No caso do pimenteiro não é diferente onde se tem adotado técnicas de manejo que propiciem ao produtor incrementos na produtividade, melhoria da qualidade do produto, além de redução dos custos de produção. Dentro deste contexto algumas técnicas de manejo já são conhecidas e adotadas pelos produtores, como o cultivo em ambiente protegido, a fertirrigação e enxertia.

A enxertia é uma técnica muito utilizada no pimenteiro, onde no ano de 2008/2009 o pimenteiro teve 2.447.670 de mudas enxertadas nesse período (Goto, 2011). Mostrando assim a importância que a enxertia tem nos dias atuais na vida dos produtores.

De acordo com Lee (1994), Oda (1995) e Miguel (1997), os métodos tradicionais de enxertia são: fenda simples, encostia, inserção lateral com e sem enraizamento das mudas, contato em bisel e corte horizontal.

A parte aérea das plantas enxertadas pode apresentar mudanças na concentração e na quantidade de vários elementos minerais, em razão de um impedimento na conexão vascular do xilema e floema, ocorrido durante o processo de união entre o porta-enxerto e enxerto (Cañizares \& Villas Bôas, 2003).

No pimentão, existem poucos estudos a respeito dos teores de macronutrientes em plantas enxertadas para avaliar sua deficiência ou suficiência. Segundo Marcussi (2005) a análise química do tecido vegetal torna-se um procedimento recomendado para comparação dos teores dos macronutrientes com os valores críticos para a cultura. Portanto o teor adequado de cada nutriente na cultura do pimenteiro fornece informações importantes para o conhecimento das proporções de nutrientes a serem aplicadas durante a fertirrigação.

Marcussi (2005) destaca a importância dos estudos de avaliação do estado nutricional das plantas, isso porque, quanto maior a capacidade da planta em acumular um nutriente, maiores serão as diferenças na concentração desse nutriente em resposta a taxas variáveis de adubação. $\mathrm{O}$ conhecimento da exigência nutricional e da concentração dos nutrientes por meio de órgãos representativos nas plantas é importante para estabelecer as quantidades de nutrientes a serem aplicadas por meio dos fertilizantes, obtendo, assim, melhores rendimentos. 
Devido à grande importância de se determinar até que ponto a enxertia pode influenciar no transporte e translocação dos nutrientes, este trabalho teve o objetivo em determinar os teores de macronutrientes $(\mathrm{N}, \mathrm{P}, \mathrm{K}, \mathrm{Ca}, \mathrm{Mg}$ e $\mathrm{S})$ nos diferentes órgãos do híbrido de pimentão AF 7125, enxertadas pelos métodos de enxertia inserção lateral, garfagem por fenda cheia e encostia, sob fertirrigação em ambiente protegido.

\section{MATERIAL E MÉTODOS}

O experimento foi conduzido em ambiente protegido, na Fazenda de Ensino, Pesquisa e Produção São Manuel, no município de São Manuel - SP $\left(22^{\circ} 44^{\prime}\right.$ S, $48^{\circ} 34^{\prime}$ W e 750 m de altitude) pertencente à FCA-UNESP, Campus de Botucatu - SP, durante cinco meses. Utilizou-se uma estrutura do tipo arco de 7,0 x 40,0 m com pé direito de 3,0 m, coberto por filme de polietileno de baixa densidade (PEBD), transparente, de $150 \mu \mathrm{m}$ de espessura.

O solo do ambiente protegido é classificado como Latossolo Vermelho Amarelo fase arenosa (Embrapa, 2006). É possível observar as características do solo conforme análise de solo realizada antes do transplante das mudas (Tabela 1).

Tabela 1. Características químicas do solo.

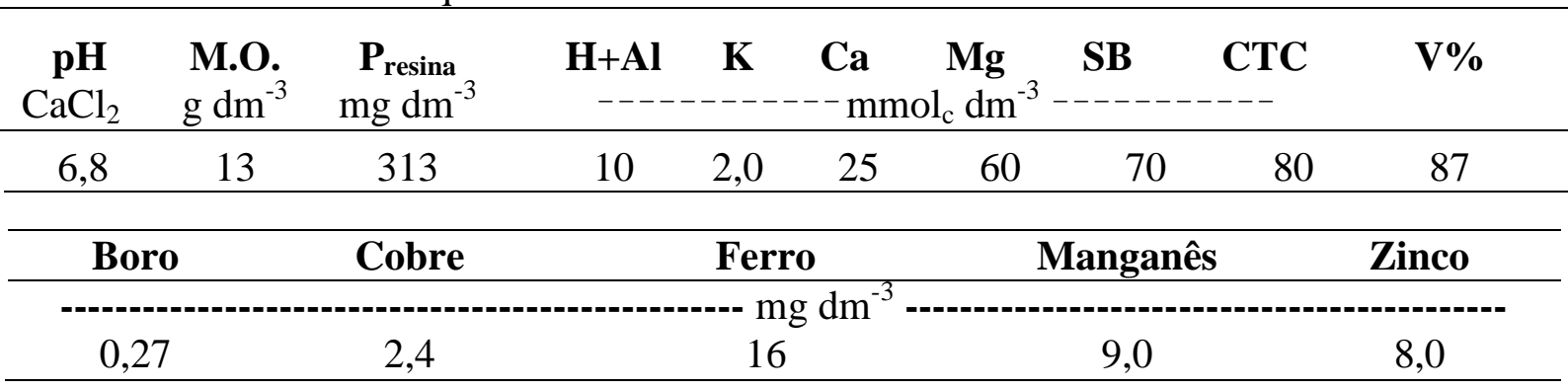

$\mathrm{Na}$ adubação de base foi adicionado apenas $3 \mathrm{~kg}$ por $\mathrm{m}^{2}$ do composto orgânico "Provaso ${ }^{\circledR} "$ (produto que apresenta a composição de $40-45 \%$ de matéria orgânica, $1-2 \%$ de nitrogênio, $0,8-1,3 \%$ de fósforo total, $0,5-0,8 \%$ de potássio, $5-6 \%$ de cálcio, umidade de $35-40 \%$ e pH $7-8$ ). As leiras de plantio foram feitas nas seguintes dimensões: 40 x 0,5 x $0,5 \mathrm{~m}$, comprimento, largura e altura respectivamente.

O delineamento experimental utilizado foi de blocos ao acaso, com quatro tratamentos, sendo plantas não enxertadas (pé-franco) e plantas enxertadas (Contato bisel, garfagem por fenda cheia e encostia) em cinco repetições, sendo cada parcela experimental constituída por 12 plantas, com espaçamento de $1,10 \times 0,50 \mathrm{~m}$.

As enxertias foram realizadas quando o porta-enxerto (AF 8253) e o híbrido (AF 7125) usado como enxerto apresentavam sete e três folhas expandidas respectivamente. $\mathrm{O}$ método contato em bisel consiste em fazer cortes em bisel no enxerto e porta-enxerto unindoos posteriormente com auxilio de clipe para enxertia. Na garfagem por fenda cheia faz-se um corte no enxerto e porta-enxerto acima das folhas cotiledonares com auxílio de um aparelho composto por duas lâminas.

$\mathrm{Na}$ encostia faz-se um corte de $1,5 \mathrm{~cm}$ para baixo no porta-enxerto logo acima dos cotilédones e um corte de $1,5 \mathrm{~cm}$ para cima no enxerto acima dos cotilédones, depois encaixa as plantas. Após sete dias da enxertia, deve-se realizar o "desmame", ou seja, cortar o hipocótilo das plantas de pimenteiro logo abaixo do ponto de enxertia. 
Após o transplante, foram realizados os tratos culturais, de acordo com a necessidade da cultura, eliminando-se todos os brotos laterais que se formaram abaixo da primeira bifurcação, enquanto estes ainda pequenos. O sistema de condução adotado para o pimentão foi em "V", de acordo com Tivelli (1999). Com relação à irrigação, esta foi realizada via sistema de gotejamento, composta por uma fita gotejadora por leira, sendo a irrigação realizada de acordo com as leituras dos tensiômetros de mercúrio. Foi feito o monitoramento do $\mathrm{pH}$ e da condutividade elétrica da solução do solo semanalmente.

As fertirrigações foram realizadas três vezes semanais e a quantidade de fertilizantes em função do ciclo de cultivo, da análise de solo, encontram-se na Tabela 2.

Tabela 2. Quantidade de fertilizantes (kg/240 plantas) fornecidos via fertirrigação durante o ciclo da cultura.

\begin{tabular}{cccc}
\hline Fertilizantes & $\mathbf{1}^{\text {a }}$ Fase- até 50DAT & $\begin{array}{c}\mathbf{2}^{\text {a }} \text { Fase-50 a 90 } \\
\text { DAT }\end{array}$ & $\begin{array}{c}\mathbf{3}^{\text {a }} \text { Fase }-90 \text { a 165 } \\
\text { DAT }\end{array}$ \\
\hline Nitrato de Cálcio & 5 & 10 & 25 \\
Nitrato de Potássio & 5 & 7 & 15 \\
Sulfato de Potássio & - & 4 & 7 \\
MAP & 1,1 & 2 & 7 \\
Sulfato de Magnésio & 2 & 4 & 15 \\
\hline
\end{tabular}

Foram realizadas adubações complementares com: sulfato de zinco - 3 aplicações de 350 gramas cada; ácido bórico- 3 aplicações de 100 gramas cada e foram realizadas cinco aplicações foliares de Yogen $5\left(\mathrm{~N}-20 \% ; \mathrm{P}_{2} \mathrm{O}_{5^{-}} 5 \%\right.$; $\mathrm{K}_{2} \mathrm{O}-10 \%$; Mg- $1 \%$ : S- $5 \%$; B- $1 \%$; Cu- 0,05\%; Mn- 0,1\%; Mo- 0,01 \% e Zn- $7 \%$ ) .

Aos 35, 85, 112 e 143 dias após transplante (DAT), as plantas foram coletadas e separadas em parte vegetativa (folha + caule) e frutos. Posteriormente esse material foi lavado em água corrente e água destilada, posteriormente o material foi levado para secagem em estufa $\left(65^{\circ} \mathrm{C}\right)$, moído e analisado quimicamente, segundo metodologia de Malavolta et al. (1997). As plantas retiradas aos 35 DAT não tiveram frutos para a análise. As plantas coletadas aos 85 DAT haviam produzidos frutos de uma colheita e as plantas aos 112 e 143 DAT produziram frutos em 6 e 8 colheitas respectivamente.

$\mathrm{Na}$ análise química foi determinado os teores de macronutrientes $(\mathrm{N}, \mathrm{P}, \mathrm{K}, \mathrm{Ca}, \mathrm{Mg}$ e S) na parte vegetativa (folha + caule) e frutos, sendo os resultados submetidos à análise de variância, com teste $\mathrm{F}$, e as médias comparadas pelo teste de Tukey, a 5\% de probabilidade, com auxílio do software S.A.S. para Windows, versão 9.2.

\section{RESULTADOS E DISCUSSÃO}

Na Tabela 3 estão apresentados os teores de nitrogênio $(\mathrm{N})$ na parte vegetativa (folhas + caule) de plantas de pimentão enxertadas e não enxertadas. $\mathrm{O}$ maior teor de $\mathrm{N}$ foi encontrado aos 35 DAT e não foi evidenciada nenhuma diferença entre as plantas não enxertadas e plantas enxertadas demostrando que não havia diferença na absorção e translocação utilizando tipos distintos de enxertia, onde já havia uma compatibilidade entre porta-enxerto e enxerto conforme Kawaguchi et al. (2008) observaram em solanáceas (pimenteira e tomateiro) . 
Tabela 3. Teor de nitrogênio na parte vegetativa do pimentão em diferentes tempos em função dos métodos de enxertia.

\begin{tabular}{|c|c|c|c|c|}
\hline \multirow{2}{*}{ Tratamento } & \multicolumn{4}{|c|}{ 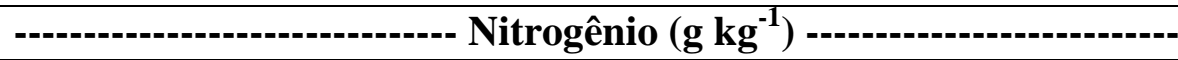 } \\
\hline & 35 DAT & 85 DAT & 112 DAT & 143 DAT \\
\hline Pé-franco & 36 & 28 & 24 & 27 \\
\hline Contato bisel & 38 & 29 & 24 & 29 \\
\hline Fenda cheia & 38 & 29 & 23 & 27 \\
\hline Encostia & 38 & 30 & 26 & 27 \\
\hline $\mathrm{F}$ & $1,13^{\mathrm{ns}}$ & $1,06^{\mathrm{ns}}$ & $1,70^{\mathrm{ns}}$ & $0,94^{\mathrm{ns}}$ \\
\hline $\mathrm{CV}(\%)$ & 5,82 & 8,07 & 9,82 & 8,64 \\
\hline DMS & 4,16 & 4,45 & 4,58 & 4,53 \\
\hline
\end{tabular}

ns = não significativo

Santos (2005) utilizando combinações de dois porta-enxertos com dois híbridos de pimentão também não verificou diferença nos teores de $\mathrm{N}$ em todas as combinações enxertadas e não enxertadas, encontrando os maiores valores desse elemento ao longo do ciclo aos 35 DAT. Brandão Filho et al. (2003) trabalhando com berinjela e Branco et al. (2007) com tomate, verificaram que plantas enxertadas e não enxertadas têm a mesma eficiência em absorver e assimilar o nitrogênio. Outro aspecto importante é que o $\mathrm{N}$ foi o segundo nutriente com maior teor, fato este observado por Villas Bôas (2001), Marcussi (2005) e Santos (2005).

$\mathrm{O}$ fósforo $(\mathrm{P})$ é um macronutriente aniônico pouco exigido pelas plantas, com teores inferiores ao do $\mathrm{N}, \mathrm{K}, \mathrm{Ca}$ e $\mathrm{Mg}$, igualando-se à do S. Isso foi observado neste trabalho, onde o $\mathrm{P}$ teve menor absorção quantitativa durante o ciclo .Os teores estão apresentados na Tabela 4, onde pode-se observar que $\mathrm{P}$ não foi influenciado pelos métodos de enxertia, sendo o maior valor na primeira coleta, aos 35 DAT, quando atingiu o valor médio de $4,45 \mathrm{~g} \mathrm{~kg}^{-1}$, em seguida os valores decresceram em relação aos demais períodos de amostragem.

Tabela 4. Teor de Fósforo na parte vegetativa do pimentão em diferentes tempos em função dos métodos de enxertia.

\begin{tabular}{|c|c|c|c|c|}
\hline \multirow{2}{*}{ Tratamento } & \multicolumn{4}{|c|}{ - } \\
\hline & 35 DAT & 85 DAT & 112 DAT & 143 DAT \\
\hline Pé-franco & 4,5 & 2,8 & 2,8 & 2,7 \\
\hline Contato bisel & 4,4 & 2,6 & 2,6 & 2,8 \\
\hline Fenda cheia & 4,4 & 2,5 & 2,7 & 3,0 \\
\hline Encostia & 4,5 & 2,5 & 2,8 & 2,8 \\
\hline $\mathrm{F}$ & $0,45^{\mathrm{ns}}$ & $0,79^{\mathrm{ns}}$ & $0,40^{\mathrm{ns}}$ & $0,97^{\mathrm{ns}}$ \\
\hline $\mathrm{CV}(\%)$ & 3,56 & 14,65 & 14,89 & 9,88 \\
\hline DMS & 0,30 & 0,71 & 0,76 & 0,52 \\
\hline
\end{tabular}

ns $=$ não significativo

Nas outras coletas o baixo teor de $\mathrm{P}$, pode ter ocorrido devido ao $\mathrm{pH}$ elevado da solução do solo, possivelmente pelo uso de fontes nítricas e estas podendo contribuir assim para menor concentração de P nas folhas (Villas Bôas, 2001), devido a baixa disponibilidade desse nutriente em $\mathrm{pH}$ alcalino. $\mathrm{O}$ pH da solução do solo variou entre 6,8 a 7,3. 
Kawaguchi et al. (2008) concluiu que o porta-enxerto é o principal fator que afeta o absorção e translocação de $\mathrm{P}$ nas combinações com $\mathrm{o}$ enxerto nas solanáceas. As concentrações de $\mathrm{P}$ nas folhas e caules de plantas de pepino foram afetadas significativamente pela enxertia, a maior concentração de $\mathrm{P}$ se deu nas plantas enxertadas quando comparadas com as plantas não enxertadas (Rouphael et al., 2008).

Resultados similares foram obtidos para concentrações de $\mathrm{P}$ nas folhas de plantas enxertadas de melancia (Colla et al., 2010) e tomate (Fernández-García et al., 2004), demonstrando que a combinação do porta-enxerto pode afetar a absorção de $\mathrm{P}$ de forma positiva. Neste trabalho não foi evidenciado nenhum efeito do porta-enxerto na absorção e translocação de $\mathrm{P}$ que resultasse em maior concentração desse nutriente na parte vegetativa (folha + caule) das plantas enxertadas.

Para teor de potássio (K) houve efeito significativo entre os tratamentos somente aos 85 DAT, onde o tratamento contato em bisel teve maior concentração de $\mathrm{K}$ diferindo do tratamento encostia e da fenda cheia, entretanto as plantas não enxertadas não demonstraram diferença no acúmulo deste elemento comparando-se com os outros tratamentos, apresentando desta forma valores intermediários (Tabela 5).

Tabela 5. Teor de Potássio na parte vegetativa do pimentão em diferentes tempos em função dos métodos de enxertia.

\begin{tabular}{|c|c|c|c|c|}
\hline \multirow{2}{*}{ Tratamento } & \multicolumn{4}{|c|}{ 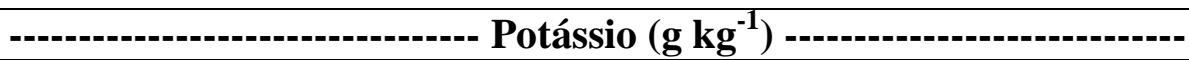 } \\
\hline & 35 DAT & 85 DAT & 112 DAT & 143 DAT \\
\hline Pé-franco & 58 & $53 \mathrm{ab}$ & 46 & 45 \\
\hline Contato bisel & 61 & $55 \mathrm{a}$ & 46 & 40 \\
\hline Fenda cheia & 58 & $50 \mathrm{~b}$ & 46 & 46 \\
\hline Encostia & 56 & $50 \mathrm{~b}$ & 48 & 44 \\
\hline $\mathrm{F}$ & $1,02^{\mathrm{ns}}$ & $4,68 *$ & $0,29^{\mathrm{ns}}$ & $0,24^{\mathrm{ns}}$ \\
\hline $\mathrm{CV}(\%)$ & 7,35 & 4,83 & 10,29 & 8,95 \\
\hline DMS & 8,01 & 4,71 & 9,07 & 7,57 \\
\hline
\end{tabular}

Médias seguidas de mesma letra minúscula na coluna não diferem entre si, pelo teste Tukey a $1 \%$ pelo teste $\mathrm{F}$.

Segundo Cañizares e Villas Bôas (2003) em plantas enxertadas, a translocação de nutrientes e a movimentação de água dentro da planta podem ser prejudicadas em razão de um bloqueio parcial na união do enxerto, resultando assim em acúmulo de solutos na região de enxertia. Outro aspecto a considerar é a diferença de concentração de K entre porta-enxerto e enxerto, assim maior ou menor concentração de $\mathrm{K}$ em plantas enxertadas pode estar relacionada com a concentração desse nutriente presente no porta-enxerto. As características físicas e fisiológicas de porta-enxertos, provavelmente afeta a absorção e translocação dos nutrientes nas plantas.

Tem sido observado em porta-enxertos de cucurbitáceas e solanáceas maiores teores de alguns nutrientes como, por exemplo, $\mathrm{N}, \mathrm{K}, \mathrm{Mg}$, e que o estado nutricional das plantas enxertadas devem estar em estrita relação com a combinação do porta-enxerto com enxerto (Cañizares \& Villas Bôas, 2003). Em plantas de pepino enxertadas houve aumento significativo no conteúdo de $\mathrm{K}$ em quase todos os tecidos de plantas, exceto nos frutos que pode ter sido influenciado pela enxertia (Rouphael et al., 2008).

Os teores de Cálcio (Ca) estão apresentados na Tabela 6, não foi demonstram nenhuma diferença entre os tratamentos para esse nutriente. 
Tabela 6. Teor de Cálcio na parte vegetativa do pimentão em diferentes tempos em função dos métodos de enxertia.

\begin{tabular}{|c|c|c|c|c|}
\hline \multirow{2}{*}{ Tratamento } & \multicolumn{4}{|c|}{ 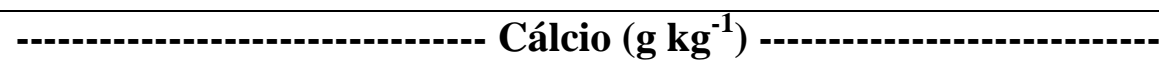 } \\
\hline & 35 DAT & 85 DAT & 112 DAT & 143 DAT \\
\hline Pé-franco & 20 & 29 & 24 & 30 \\
\hline Contato bisel & 19 & 31 & 29 & 29 \\
\hline Fenda cheia & 19 & 32 & 27 & 30 \\
\hline Encostia & 20 & 31 & 28 & 33 \\
\hline $\mathrm{F}$ & $0,41^{\mathrm{ns}}$ & $2,74^{\mathrm{ns}}$ & $1,16^{\mathrm{ns}}$ & $2,10^{\mathrm{ns}}$ \\
\hline CV (\%) & 9,95 & 5,65 & 13,57 & 9,73 \\
\hline DMS & 3,66 & 3,26 & 6,93 & 5,57 \\
\hline
\end{tabular}

ns = não significativo

Característica semelhante foi obtida para cucurbitáceas segundo Colla et al. (2010) em melancia e Rouphael et al. (2008) em pepino e para solanáceas Chen et al. (2003) em tomate e Santos (2005) para pimentão comparando-se plantas não enxertadas com plantas enxertadas.

$\mathrm{O}$ Ca tem como característica concentrar-se na sua maior parte em folhas e caules (Marcussi et al., 2004; Santos, 2005). Neste trabalho, também foi constatada esta tendência por parte das plantas enxertadas e não enxertadas.

Para nutriente $\mathrm{Mg}$, observa-se que houve diferença entre os tratamentos para todas as épocas de avaliação para parte vegetativa (folha + caule). Aos 35 DAT as plantas enxertadas tiveram resultados semelhantes não havendo diferença estatística entre si, porém a encostia teve maior valor diferindo do pé-franco.

Na segunda avaliação aos 85 DAT nota-se a mesma situação com relação aos 35 DAT, onde as plantas enxertadas tiveram maior concentração desse elemento quando comparadas com o pé-franco, sendo que somente a encostia teve resultado semelhante ao pé-franco, contudo, apresentando maiores valores absolutos utilizando-se a encostia. Essa tendência das plantas enxertadas ter maior teor nas folhas + caules podem ser observadas também aos $112 \mathrm{e}$ 143 DAT onde as mesma diferiram estatisticamente das plantas não enxertadas tendo maior concentração de Mg (Tabela 7).

Tabela 7. Teor de Magnésio na parte vegetativa do pimentão em diferentes tempos em função dos métodos de enxertia.

\begin{tabular}{|c|c|c|c|c|}
\hline \multirow{2}{*}{ Tratamento } & \multicolumn{4}{|c|}{ - } \\
\hline & 35 DAT & 85 DAT & 112 DAT & 143 DAT \\
\hline Pé-franco & $5,6 \mathrm{~b}$ & $5,4 \mathrm{~b}$ & $4,9 \mathrm{~b}$ & $5,6 \mathrm{~b}$ \\
\hline Contato bisel & $7,0 \mathrm{ab}$ & $6,9 \mathrm{a}$ & $6,4 \mathrm{a}$ & $6,9 \mathrm{a}$ \\
\hline Fenda cheia & $6,8 \mathrm{ab}$ & $7,3 \mathrm{a}$ & $6,3 \mathrm{a}$ & $7,0 \mathrm{a}$ \\
\hline Encostia & $7,2 \mathrm{a}$ & $6,5 \mathrm{ab}$ & $6,3 \mathrm{a}$ & $7,2 \mathrm{a}$ \\
\hline $\mathrm{F}$ & $3,91^{*}$ & $5,80^{*}$ & $5,14^{*}$ & $6,74^{* *}$ \\
\hline $\mathrm{CV}(\%)$ & 12,57 & 11,47 & 12,21 & 9,22 \\
\hline DMS & 1,57 & 1,41 & 1,37 & 1,15 \\
\hline
\end{tabular}

Médias seguidas de mesma letra minúscula na coluna não diferem entre si, pelo teste Tukey a $5 \%{ }^{* *}$ significativo a $1 \%,{ }^{*}$ significativo a $5 \%$ pelo teste $\mathrm{F}$. 
Essas diferenças entre plantas enxertadas e o pé-franco, possivelmente pode ser que as raízes do porta-enxerto tenham extraído e translocado maior quantidade desse elemento para folhas + caules que as raízes do pé-franco. Estudos com plantas de melancia enxertadas em abóbora demonstram maior teor deste nutriente do que quando enxertado na cabaça como porta-enxerto (Colla et al., 2010).

Os resultados referentes ao teor de enxofre (S) encontra se na Tabela 8, onde não foi observado em nenhuma avaliação, diferenças no teor de $\mathrm{S}$ entre os tratamentos.

Tabela 8. Teor de Enxofre na parte vegetativa do pimentão em diferentes tempos em função dos métodos de enxertia.

\begin{tabular}{|c|c|c|c|c|}
\hline \multirow{2}{*}{ Tratamento } & \multicolumn{4}{|c|}{------------------------------Enxofre $\left(\mathrm{g} \mathrm{kg}^{-1}\right)$} \\
\hline & 35 DAT & 85 DAT & 112 DAT & 143 DAT \\
\hline Pé-franco & 3,1 & 3,2 & 3,6 & 4,2 \\
\hline Contato bisel & 3,3 & 3,4 & 3,7 & 4,4 \\
\hline Fenda cheia & 3,4 & 3,4 & 3,7 & 4,4 \\
\hline Encostia & 3,4 & 3,3 & 3,7 & 4,2 \\
\hline $\mathrm{F}$ & $1,57^{\mathrm{ns}}$ & $2,25^{\mathrm{ns}}$ & $0,14^{\mathrm{ns}}$ & $1,24^{\mathrm{ns}}$ \\
\hline $\mathrm{CV}(\%)$ & 8,86 & 3,83 & 8,24 & 6,21 \\
\hline DMS & 0,54 & 0,23 & 0,56 & 0,5 \\
\hline
\end{tabular}

ns = não significativo

Com relação às concentrações dos macronutrientes Marcussi (2005) trabalhando com pimentão (híbrido Elisa) utilizando fertirrigação encontrou aos 140 DAT, as seguintes concentrações dos macronutrientes em $\mathrm{g} \mathrm{kg}^{-1}: 39,9$ de $\mathrm{K} ; 28,3$ de $\mathrm{N} ; 12,8$ de $\mathrm{Ca}$; 5,9 de $\mathrm{Mg}$; 4,1 de $\mathrm{S}$ e 3,7 de $\mathrm{P}$.

Neste estudo o híbrido de pimentão pé-franco AF 7125 aos 143 DAT apresentaram as seguintes concentrações dos macronutrientes em $\mathrm{g} \mathrm{kg}^{-1}$ : 49, 7 de $\mathrm{K} ; 28,75$ de $\mathrm{N} ; 25,75$ de Ca; 5,4 de $\mathrm{Mg} ; 3,7$ de $\mathrm{S}$ e 3,2 de P. As plantas enxertadas foram: 49, 4 de $\mathrm{K} ; 30$ de N; 27,33 de $\mathrm{Ca}$; 6,8 de $\mathrm{Mg}$; 3,7 de $\mathrm{S}$ e 3,1 de $\mathrm{P}$, não sendo observado diferenças nos teores entre as plantas enxertadas e o pé-franco. Dessa forma o único elemento que sofreu grande variação foi o $\mathrm{Ca}$, que apresentou aumento no valor superior a $100 \%$, o que pode ser devido a diferença dos órgãos analisados, pois neste caso avaliou-se apenas caules e folhas e Marcussi (2005) avaliou a planta inteira, sendo os resultados obtidos por estes autores provenientes da média encontrada.

Analisando os frutos observou-se que somente na última avaliação houve diferença no teor de $\mathrm{Mg}$, sendo que o pé-franco teve maior concentração que as plantas enxertadas por contato bisel. O maior teor de Mg também foi observado por Macedo Júnior (1998), onde observou aumento da concentração de magnésio em plantas de pepino enxertado em abóbora à medida que as plantas foram se desenvolvendo durante o ciclo da cultura. Cañizares (2001) observou o aumento do $\mathrm{Mg}$ na fase final do ciclo da cultura, sendo que, as plantas não enxertadas (pé-franco) tiveram um aumento da concentração sensivelmente maior que as plantas enxertadas. 
Tabela 9. Teores de macronutrientes em frutos de pimentão enxertados e não enxertados aos 85,112 e 143 dias após o transplante das mudas.

\begin{tabular}{|c|c|c|c|c|c|c|}
\hline \multirow{3}{*}{ Tratamento } & \multicolumn{5}{|c|}{85 DAT } & \multirow[b]{2}{*}{$\mathbf{S}$} \\
\hline & $\mathbf{N}$ & $\mathbf{P}$ & $\mathbf{K}$ & $\mathbf{C a}$ & Mg & \\
\hline & \multicolumn{6}{|c|}{ 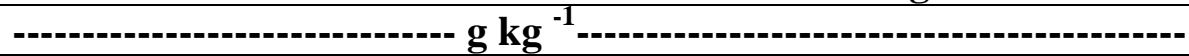 } \\
\hline Pé-franco & 23 & 3,7 & 39 & 2 & 2 & 2,1 \\
\hline Contato bisel & 24 & 3,8 & 40 & 2 & 2 & 2,1 \\
\hline Fenda cheia & 22 & 4,2 & 39 & 2 & 2,1 & 2 \\
\hline Encostia & 22 & 4,4 & 38 & 2 & 1,9 & 2 \\
\hline $\mathrm{F}$ & $0,91^{\mathrm{ns}}$ & $1,52^{\mathrm{ns}}$ & $0,19^{\mathrm{ns}}$ & $1,0^{\mathrm{ns}}$ & $0,46^{\mathrm{ns}}$ & $0,45^{\mathrm{ns}}$ \\
\hline $\mathrm{CV}(\%)$ & 9,47 & 13,33 & 12,08 & 22,89 & 12,93 & 6,96 \\
\hline DMS & 4,1 & 1,01 & 8,81 & 0,75 & 0,48 & 0,26 \\
\hline \multicolumn{7}{|c|}{112 DAT } \\
\hline Pé-franco & 14 & 2,9 & 28 & 1 & 1,3 & 2 \\
\hline Contato bisel & 14 & 3 & 25 & 1 & 1,3 & 1,8 \\
\hline Fenda cheia & 13 & 2,8 & 25 & 1 & 1,3 & 1,8 \\
\hline Encostia & 14 & 2,8 & 25 & 1 & 1,3 & 1,8 \\
\hline $\mathrm{F}$ & $0,23^{\mathrm{ns}}$ & $1,54^{\mathrm{ns}}$ & $3,20^{\mathrm{ns}}$ & $1,72^{\mathrm{ns}}$ & $0,11^{\mathrm{ns}}$ & $2,18^{\mathrm{ns}}$ \\
\hline $\mathrm{CV}(\%)$ & 12,59 & 6,42 & 8,1 & 30,93 & 13,43 & 11,3 \\
\hline DMS & 3,58 & 0,35 & 3,91 & 0,52 & 0,32 & 0,38 \\
\hline \multicolumn{7}{|c|}{143 DAT } \\
\hline Pé-franco & 17 & 3,1 & 30 & 1 & $1,5 \mathrm{a}$ & 2 \\
\hline Contato bisel & 15 & 3,2 & 27 & 1 & $1,3 \mathrm{~b}$ & 1,8 \\
\hline Fenda cheia & 18 & 3,2 & 30 & 1 & $1,4 \mathrm{ab}$ & 1,8 \\
\hline Encostia & 16 & 3,3 & 30 & 1 & $1,4 \mathrm{ab}$ & 1,8 \\
\hline $\mathrm{F}$ & $0,91^{\mathrm{ns}}$ & $0,76^{\mathrm{ns}}$ & $1,77^{\mathrm{ns}}$ & $1,40^{\mathrm{ns}}$ & $3,60^{*}$ & $1,75^{\mathrm{ns}}$ \\
\hline $\mathrm{CV}(\%)$ & 18,38 & 3,92 & 8,19 & 21,81 & 6,57 & 7,28 \\
\hline DMS & 5,77 & 0,24 & 4,38 & 0,4 & 0,17 & 0,27 \\
\hline
\end{tabular}

Médias seguidas de mesma letra minúscula na coluna não diferem entre si, pelo teste Tukey a $5 \%{ }^{* *}$ significativo a $1 \%$ pelo teste $\mathrm{F}$.

Constatou-se que todos os tratamentos apresentaram a mesma distribuição percentual, revelando que a enxertia não provocou nenhuma alteração nesse aspecto. Concordando com Santos (2005) que estudou em plantas enxertadas e não enxertadas mostrando que a enxertia não influenciou na alteração deste aspecto.

A concentração média na parte vegetativa (folha + caule) foram as seguintes: $68,9 \%$ de $\mathrm{N}, 56,52 \%$ de $\mathrm{P}, 68,14 \%$ de $\mathrm{K}, 84,58 \%$ de $\mathrm{Mg}, 96,46 \%$ de $\mathrm{Ca}$ e 71,22\% de $\mathrm{S}$ e nos frutos foram: $31,10 \%$ de N, 43,48 \% de P, 31,86\% de K, 15,42\% de Mg, 3,54\% de Ca, $28,78 \%$ de $\mathrm{S}$ (Gráfico 1). 


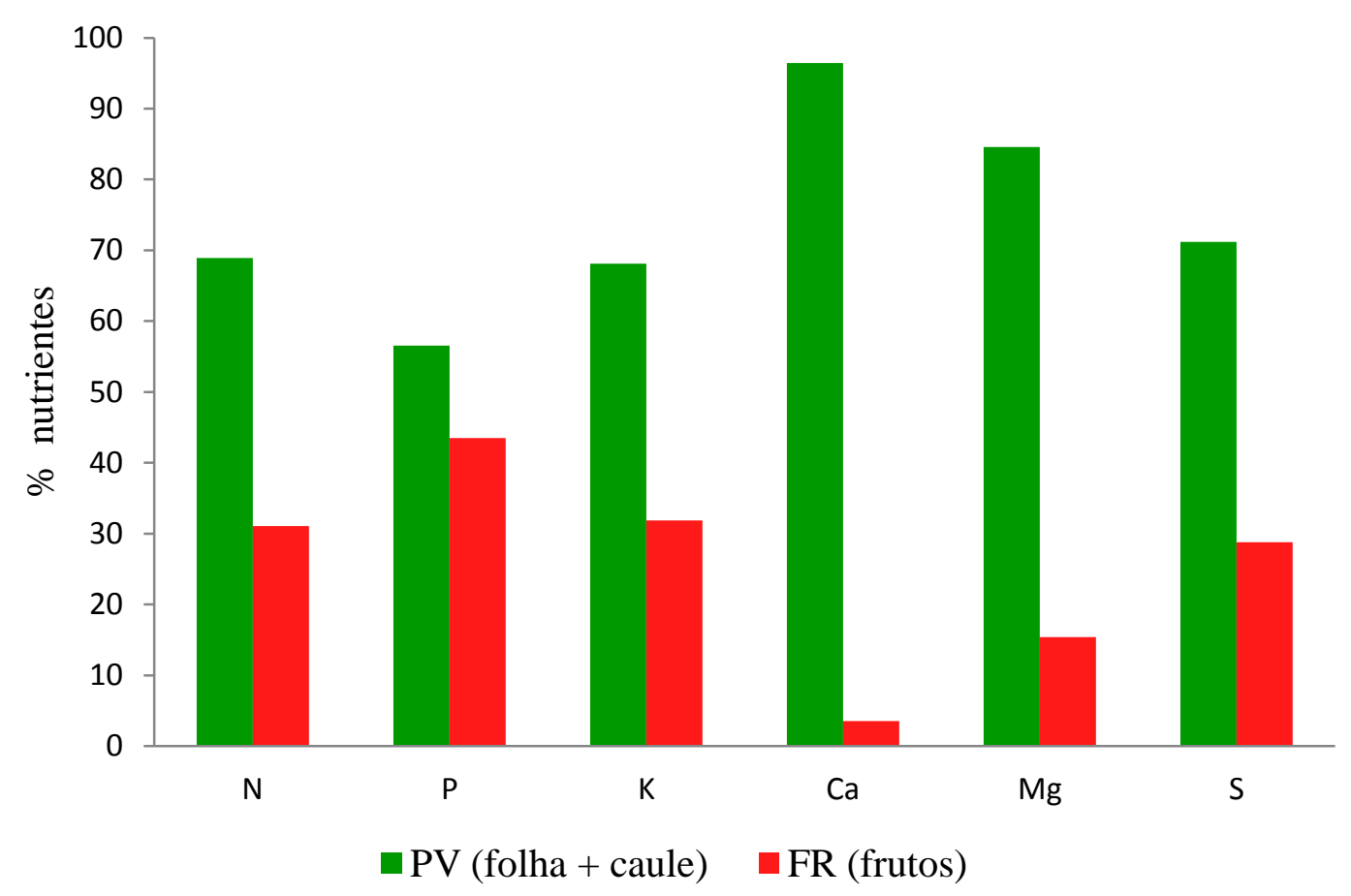

Figura 1. Distribuição percentual na parte vegetativa e nos frutos de plantas de pimentão.

$\mathrm{O} \mathrm{Ca}$ e o $\mathrm{Mg}$ são os macronutrientes que se concentraram em maior quantidade nas folhas e em menor quantidade nos frutos. Esses resultados são coerentes com outros autores Santos (2005) e Silva (1998).

O genótipo de pimentão utilizado pode influenciar variações nos percentuais de distribuição. De maneira geral, plantas de pimentão seguem uma tendência padrão de concentração de nutrientes em diferentes partes das plantas. Os resultados obtidos do teor dos macronutrientes permitem melhor monitoramento do estado nutricional da planta de pimentão nos diferentes estádios fenológicos da cultura, visando melhor manejo nutricional das plantas com aplicação dos fertilizantes via água de irrigação.

\section{CONCLUSÕES}

Nas condições testadas no presente estudo, conclui-se que:

- A concentração dos macronutrientes foi equivalente entre as plantas enxertadas e plantas péfranco.

- A ordem de concentração de macronutrientes na parte vegetativa (folha + caule) do híbrido AF 7125 sob fertirrigação foi: $\mathrm{K}>\mathrm{N}>\mathrm{Ca}>\mathrm{Mg}>\mathrm{S}>\mathrm{P}$; já nos frutos foi: $\mathrm{K}>\mathrm{N}>\mathrm{P}>\mathrm{S}>$ $\mathrm{Mg}>\mathrm{Ca}$.

- O Mg teve sua maior concentração nas plantas enxertadas do que nas não enxertadas em todas as coletas.

\section{REFERÊNCIAS BIBLIOGRÁFICAS}

AGRIANUAL. Anuário da agricultura brasileira. São Paulo: FNP - Negócios e Consultoria, 2012. 482p. 
BRANCO, R. B. F. et al. Enxertia e água de irrigação carbonatada no transporte de ${ }^{15} \mathrm{~N}$ e na produção do tomateiro. Engenharia Agrícola e Ambiental, Campina Grande, v. 11, n. 4, p. 374-379, 2007.

BRANDÃO FILHO, J. U. et al. Influência da enxertia nas trocas gasosas de dois híbridos de berinjela cultivados em ambiente protegido. Horticultura Brasileira, Brasília, v. 21, n. 3, p. 474-477, 2003.

CAÑIZARES, K. A. L. Enxertia, potássio e magnésio na nutrição, desenvolvimento e produção de pepino. 2001. 157 f. Tese (Doutorado em Agronomia/Horticultura)-Faculdade de Ciências Agronômicas, Universidade Estadual Paulista, Botucatu, 2001.

CAÑIZARES, K. A. L.; VILLAS BÔAS, R. L. Aspectos nutricionais em hortaliças enxertadas. In: GOTO, R.; SANTOS, H. S.; CAÑIZARES, K. A. L. Enxertia em hortaliças. São Paulo: UNESP, 2003. cap. 7, p. 41-45.

CHEN, G. X. et al. Control of plant growth resides in the shoot, and not in the root, in reciprocal grafts of flacca and wild-type tomato (Lycopersicon esculentum), in the presence and absence of salinity stress. Plant and Soil, Perth, v. 256, n. 1, p. 205-215, 2003.

COLLA, G. et al. The effectiveness of grafting to improve alkalinity tolerance in watermelon. Environmental and Experimental Botany, Oxford, v. 68, n. 3, p. 283-291, 2010.

COLLA, G.; SUÃREZ, C. M. C.; CARDARELLI, M.; ROUPHAEL, Y. Improving nitrogen use efficiency in melon by grafting. Horticultural Science, West Monroe, v. 45, n. 4, p. 559$565,2010$.

EMBRAPA. Sistema brasileiro de classificação de solos. 2. ed. Rio de Janeiro, 2006. 306 p.

FERNÁNDEZ-GARCÍA, N., MARTÍNEZ, V., CARVAJAL, M. Effect of salinity on growth, mineral composition, and water relations of grafted tomato plants. Journal of Plant Nutrition and Soil Science, Weinheim, v. 167, n. 5, p. 616-622, 2004.

GOTO, R. Injertos de hortalizas em Brasil, pimiento. Série Documentos, injertos de hortalizas 2011. Disponivel em: http://www.poscosecha.com/es/publicaciones/injerto-de-hortalizas-enbrasil/_id:6/ Acesso em: 11/10/2012.

KAWAGUCHI, M., TAJI, A., BACKHOUSE, D., ODA, M. Anatomy and physiology of graft incompatibility in solanaceous plants. Journal of Horticultural Science \&

Biotechnology, Dundee, v. 83, n. 5, p. 581-588, 2008.

LEE, J. M. Cultivation of grafted vegetables. 1: current status, grafting methods, and benefits. Horticultural Science, Alexandria, v. 29, p. 235-239, 1994.

MACEDO JUNIOR, E. K. Crescimento e produtividade de pepino (Cucumis sativus L.) enxertado e não enxertado, submetido à adubação convencional em cobertura e 
fertirrigação, em cultivo protegido. 1998. 129 f. Tese (Doutorado em Agronomia/Irrigação e Drenagem)-Faculdade de Ciências Agronômicas, Universidade Estadual Paulista, Botucatu, 1998.

MALAVOLTA, E.; VITTI, G. C.; OLIVEIRA, S. A. Avaliação do estado nutricional das plantas: princípios e aplicações. 2. ed. Piracicaba: POTAFOS, 1997. 201 p.

MARCUSSI, F. F. N. et al. Macronutrient accumulation and partioning In fertigated sweet pepper plants, Scienta Agrícola, Piracicaba, v. 61, n. 1, p. 62-68, 2004.

MARCUSSI, F. F. N. Uso da fertirrigação e teores de macronutrientes em planta de pimentão. Revista Engenharia Agrícola, Jaboticabal, v. 25, n. 3, p. 642-650, 2005.

MIGUEL, A. G. Injerto de hortalizas. Valencia: Generalitat Valenciana, 1997. 88 p. (Divulgación técnica, 40).

ODA, M. New grafting methods for fruit bearing vegetables in Japan. Japan Agricultural Research Quartely, Yatabe, v. 29, p. 187-94, 1995.

ROUPHAEL, Y. et al. Grafting of cucumber as a means to minimize copper toxicity. Environmental and Experimental Botany, Oxford, v. 63, n.1-3 , p.49-58, 2008.

SANTOS, H. S. Desempenho agronômico e marcha de absorção de nutrientes em plantas de pimentão (Capsicum annuum l.) enxertadas em porta-enxertos resistentes a patógenos de solo. 2005. 73 f. Tese (Doutorado em Agronomia/Horticultura)-Faculdade de Ciências Agronômicas, Universidade Estadual Paulista, Botucatu, 2005.

SILVA, M. A. G. Efeito do nitrogênio e potássio na produção e nutrição do pimentão em ambiente protegido. 1998. 86 f. Tese (Doutorado em Solos E Nutrição Mineral de Plantas)Escola Superior de Agricultura "Luiz de Queiroz", Universidade de São Paulo, Piracicaba, 1998.

TIVELLI, S. W. Sistemas de cultivo na cultura do pimentão (Capsicum annuum L.) vermelho em ambiente protegido. 1999. $157 \mathrm{f}$. Tese (Doutorado em Agronomia/ Horticultura)-Faculdade de Ciências Agronômicas, Universidade Estadual Paulista, Botucatu, 1999.

VILLAS BÔAS, R. L. Doses de nitrogênio para o pimentão aplicadas de forma convencional e através da fertirrigação. 2001. 123 f. Tese (Livre-Docência)-Faculdade de Ciências Agronômicas, Universidade Estadual Paulista, Botucatu, 2001. 